\title{
Lassa virus isolates from Mali and the Ivory Coast represent an emerging fifth lineage
}

\author{
John T. Manning, Naomi Forrester and Slobodan Paessler* \\ Department of Pathology, University of Texas Medical Branch, Galveston, TX, USA
}

Previous imported cases of Lassa fever (LF) into the United Kingdom from the Ivory Coast and Mali, as well as the detection of Lassa virus (LASV) among the Mastomys natalensis population within Mali has led to the suggestion that the endemic area for LF is expanding. Initial phylogenetic analyses arrange isolates from Mali and the Ivory Coast separately from the classical lineage IV isolates taken from Sierra Leone, Guinea, and Liberia. The availability of full genome sequences continues to increase, allowing for a more complete phylogenetic comparison of the isolates from Mali and the Ivory Coast to the other existing isolates. In this study, we utilized a Bayesian approach to infer the demographic histories of each LASV isolate for which the full sequence was available. Our results indicate that the isolates from Mali and the Ivory Coast group separately from the isolates of lineage IV, comprising a distinct fifth lineage. The split between lineages IV and $V$ is estimated to have occurred around 200-300 years ago, which coincides with the colonial period of West Africa.

Keywords: Lassa virus, Lassa fever, lineage, genetic diversity, phylogenetics

\section{Introduction}

Lassa virus (LASV) is the causative agent of Lassa fever (LF), a potentially fatal disease that infects as many as 100,000 people annually in endemic areas. Since the discovery of the virus in 1969, the endemic area for LASV has been mapped to the West African countries of Nigeria, Sierra Leone, Guinea, and Liberia (Ogbu et al., 2007). The primary natural host, Mastomys natalensis, is distributed throughout West Africa despite the constricted endemic area of LF, and infected rodents are distributed focally within the endemic area (Demby et al., 2001; Lecompte et al., 2006). However, recent cases of LF within the West African countries of Mali and the Ivory Coast suggest that the endemic area is expanding (Atkin et al., 2009; Sogoba et al., 2012).

The virus genome consists of an $\mathrm{L}$ and $\mathrm{S}$ segment, which encode the RNA-dependent RNA polymerase (LP), matrix (Z) protein, nucleoprotein (NP), and the glycoprotein precursor (GPC). Phylogenetic analyses of either partial or full-length LASV protein sequences have revealed that four lineages exist among LASV isolates. The four lineages correlate strongly with the geographic point of origin for the respective isolates (Bowen et al., 2000). While each lineage can be distinctly delineated from one another in phylogenetic analyses of each full-length gene (with the exception of the small $\mathrm{Z}$ protein), there is some variability in the relationships between individual lineages for each gene (Ehichioya et al., 2011). With full-length LASV sequences becoming more readily available, more extensive phylogenetic analyses utilizing full-length genes over a longer time frame can be performed, allowing for more complete characterization of each individual lineage. 
LASV has been suggested to have arrived in the Sierra Leone region from Nigeria between 150 and 250 years ago due to movement within the colonial period, and the recent emergence of LASV within Mali and the Ivory Coast has been suggested to be caused by movement during the Sierra Leone civil war between 1991 and 2002 (Lalis et al., 2012). The prototypic strain from the Ivory Coast, AV, was reported in 2000 as a case imported into Germany (Gunther et al., 2000). Although cases of LF have been reported in the Ivory Coast and Mali, sequencing data for isolates from these countries has only become available within the last few years (Safronetz et al., 2010, 2013). While the sequence data for these isolates has become readily available, the genetic relationship of these isolates to the classical lineages has not been completely characterized. The purpose of this study was to determine whether a fifth lineage is emerging within Mali and the Ivory Coast using analyses of complete LP, NP, and GPC genes. Using Bayesian analysis, we investigated the relationship of isolates from Mali and the Ivory Coast to all available isolates within the four traditional lineages.

\section{Methods}

\section{Sequence Alignments}

Full-length L and S segments for each available isolate were imported into SeaView 4 (Gouy et al., 2010) from GenBank (Table 1), and nucleotide sequences were aligned as amino acids using MUSCLE (Edgar, 2004), and subsequently converted back to nucleotide sequences in order to maintain third-nucleotide alignment. The resulting alignments were trimmed to include only ORFs for LP, NP, and GPC sequences and exported as nexus files for phylogenetic analysis.

\section{Phylogenetic Analysis}

Trees for LP, NP, and GPC were generated in MrBayes (Huelsenbeck and Ronquist, 2001; Ronquist and Huelsenbeck, 2003). The software utilizes a Bayesian Markov chain Monte Carlo (MCMC) algorithm to infer phylogenetic relationships. Parameters were set to utilize the invariant gamma rate of substitution model. Four chains (one hot chain and three cold chains) were utilized, and data was sampled every 100 steps. Each analysis was run for $10,000,000$ steps with burn-ins set to 250,000 steps. Data was analyzed using Tracer version 1.6 (http://tree.bio.ed.ac.uk/ software/tracer/) to confirm sufficient data sampling for each data set.

BEAST trees were generated for LP, NP, and GPC using BEAST (Drummond and Rambaut, 2007; Drummond et al., 2012). BEAST employs a Bayesian MCMC approach to infer demographic histories, evolutionary rates, and dates of divergence from serially (dated) sampled sequence data. Statistical uncertainty in the data is reflected in the $95 \%$ highest posterior density (HPD) values. Analyses were performed using the Bayesian Skyline Plot (BSP) model of population growth, which does not use a pre-specified demographic model (Drummond et al., 2005). The uncorrelated lognormal (UCLN) relaxed clock model, which allows rate variation among lineages in the phylogeny to be estimated (Drummond et al., 2006) was used. The MCMC chain was 100 million samples long, thinned to include every 5000th state in the final sample. The program Tracer version 1.6 was used to confirm stationarity. The software TreeAnnotator version 1.7.1 (http://beast.bio.ed.ac.uk/ software/TreeAnnotator) was used to summarize the data output from BEAST. The maximum clade credibility (MCC) tree was estimated using mean node heights after discarding the initial $10 \%$ of generations.

\section{Results}

\section{Bayesian Analysis Indicates the Presence of a Fifth LASV Lineage}

To begin, we first sought to determine whether there was evidence of a fifth lineage among LASV isolates using full-length NP sequences. The analysis that originally described the four classical lineages was based on partial-length NP sequences, but was later confirmed using full-length sequences from LP, NP, and GPC. While all four lineages were easily delineated from one another using full-length sequences, the relationship of each lineage to one another varied between genes (Bowen et al., 2000; Ehichioya et al., 2011). Therefore, in order to completely characterize the relationships of isolates within Mali and the Ivory Coast to the other classical isolates, we aligned the fulllength open reading frames for GPC, NP, and LP and conducted a phylogenetic analysis utilizing the Bayesian MCMC approach (MrBayes v3.2.5) for each gene.

Analysis of both the NP and GPC genes produced phylogenetic trees (Figure 1) that resemble the traditional grouping of the four lineages, with lineage I (Pinneo) creating the most basal lineage. The hierarchy continues with lineage II, lineage III (Nig08-A18, Nigo8-A19), and lineage IV. In both trees, the isolates from Mali and the Ivory Coast delineate from lineage IV distinctly with strong bootstrap support. However, analysis of full-length LP nucleotide sequences (Figure 1) places lineage II as the most basal lineage, followed by lineage I, lineage III, and lineage IV.

Within lineage IV, the Liberian isolates (Z148, Macenta, 1200LIB10) cluster together in only the LP analysis. The isolate 1200LIB10 however does share a recent common ancestor with Z148 and Macenta in the NP analysis despite being most closely related to the Sierra Leone isolates. Interestingly, the 1200LIB10 isolate clusters within the Sierra Leone isolate clade in the GPC analysis. The Guinea rodent isolate BA366 is basal to the Liberia and Sierra Leone isolates in the NP analysis, but shares a more recent common ancestor with the Sierra Leone strains with respect to Z148 and Macenta in the GPC analysis.

Five strains of LASV fell into a different grouping, designated Lineage V, these strains included AV (Ivory Coast/Ghana), BambaR114 (Mali), KominaR16 (Mali) SorombaR (Mali), and SonombaR30 (Mali). These form a single well defined lineage with high posterior probability support. All the isolates from this lineage were isolated from Mali and the Ivory Coast suggesting that this lineage is geographically restricted, maybe due to either geographical barriers or distribution of a distinct haplotype of the rodent host $M$. natalensis. 
TABLE 1 | Demographic information for each LASV isolate used in the analysis.

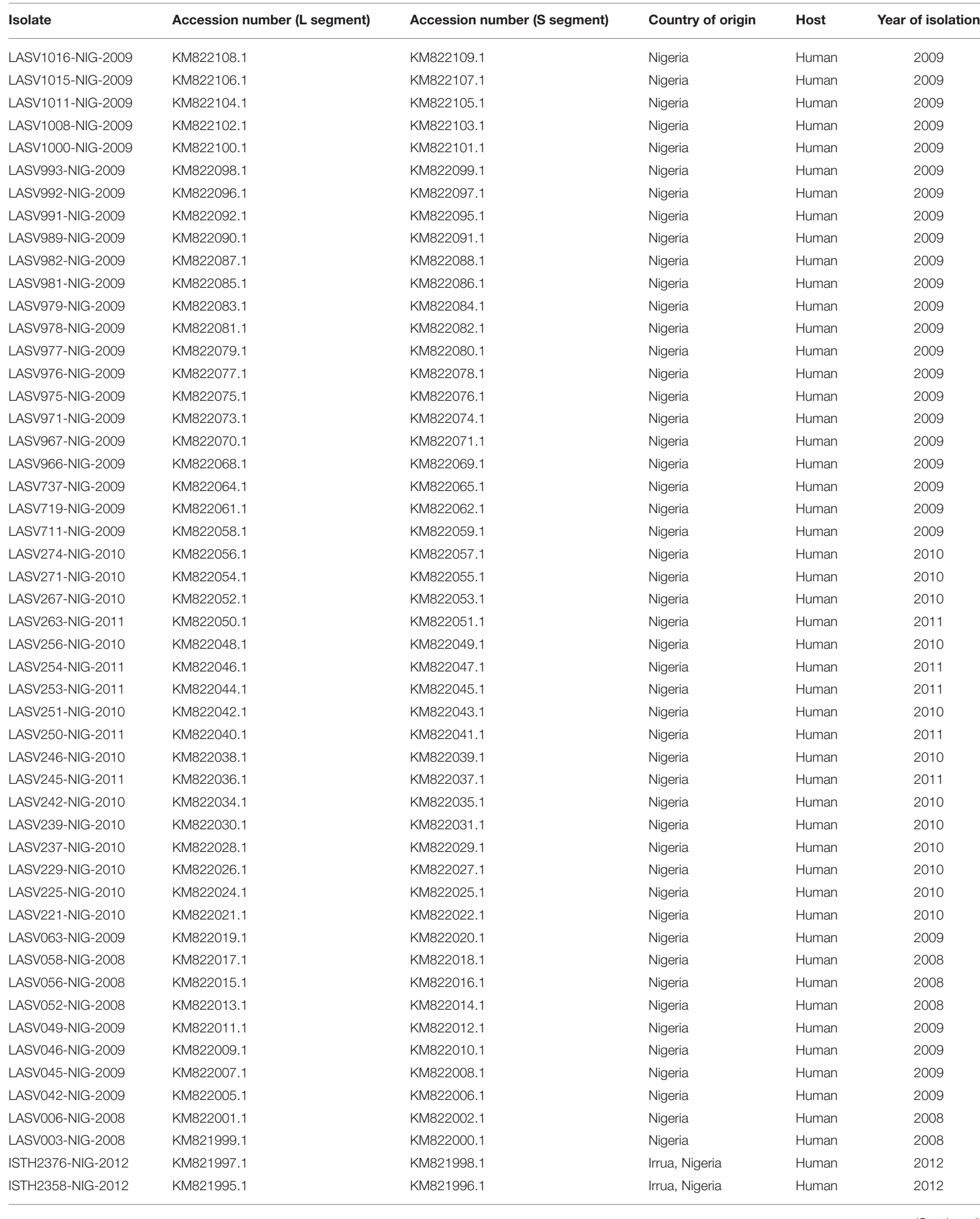


TABLE 1 | Continued

\begin{tabular}{|c|c|c|c|c|c|}
\hline Isolate & Accession number (L segment) & Accession number (S segment) & Country of origin & Host & Year of isolation \\
\hline ISTH2334-NIG-2012 & KM821993.1 & KM821994.1 & Irrua, Nigeria & Human & 2012 \\
\hline ISTH2316-NIG-2012 & KM821991.1 & KM821992.1 & Irrua, Nigeria & Human & 2012 \\
\hline ISTH2312-NIG-2012 & KM821989.1 & KM821990.1 & Irrua, Nigeria & Human & 2012 \\
\hline ISTH2304-NIG-2012 & KM821987.1 & KM821988.1 & Irrua, Nigeria & Human & 2012 \\
\hline ISTH2271-NIG-2012 & KM821985.1 & KM821986.1 & Irrua, Nigeria & Human & 2012 \\
\hline ISTH2217-NIG-2012 & KM821983.1 & KM821984.1 & Irrua, Nigeria & Human & 2012 \\
\hline ISTH2129-NIG-2012 & KM821981.1 & KM821982.1 & Irrua, Nigeria & Human & 2012 \\
\hline ISTH2094-NIG-2012 & KM821978.1 & KM821979.1 & Irrua, Nigeria & Human & 2012 \\
\hline ISTH2066-NIG-2012 & KM821975.1 & KM821976.1 & Irrua, Nigeria & Human & 2012 \\
\hline ISTH2065-NIG-2012 & KM821973.1 & KM821974.1 & Irrua, Nigeria & Human & 2012 \\
\hline ISTH2061-NIG-2012 & KM821970.1 & KM821971.1 & Irrua, Nigeria & Human & 2012 \\
\hline ISTH2046-NIG-2012 & KM821964.1 & KM821965.1 & Irrua, Nigeria & Human & 2012 \\
\hline ISTH2O42-NIG-2012 & KM821962.1 & KM821963.1 & Irrua, Nigeria & Human & 2012 \\
\hline ISTH2037-NIG-2012 & KM821960.1 & KM821961.1 & Irrua, Nigeria & Human & 2012 \\
\hline ISTH2031-NIG-2012 & KM821958.1 & KM821959.1 & Irrua, Nigeria & Human & 2012 \\
\hline ISTH2025-NIG-2012 & KM821956.1 & KM821957.1 & Irrua, Nigeria & Human & 2012 \\
\hline ISTH2020-NIG-2012 & KM821954.1 & KM821955.1 & Irrua, Nigeria & Human & 2012 \\
\hline ISTH2016-NIG-2012 & KM821952.1 & KM821953.1 & Irrua, Nigeria & Human & 2012 \\
\hline ISTH2010-NIG-2012 & KM821950.1 & KM821951.1 & Irrua, Nigeria & Human & 2012 \\
\hline ISTH1137-NIG-2011 & KM821948.1 & KM821949.1 & Irrua, Nigeria & Human & 2011 \\
\hline ISTH1129-NIG-2012 & KM821946.1 & KM821947.1 & Irrua, Nigeria & Human & 2012 \\
\hline ISTH1121-NIG-2012 & KM821944.1 & KM821945.1 & Irrua, Nigeria & Human & 2012 \\
\hline ISTH1111-NIG-2011 & KM821942.1 & KM821943.1 & Irrua, Nigeria & Human & 2011 \\
\hline ISTH1107-NIG-2012 & KM821940.1 & KM821941.1 & Irrua, Nigeria & Human & 2012 \\
\hline ISTH1096-NIG-2012 & KM821938.1 & KM821939.1 & Irrua, Nigeria & Human & 2012 \\
\hline ISTH1069-NIG-2011 & KM821936.1 & KM821937.1 & Irrua, Nigeria & Human & 2011 \\
\hline ISTH1064-NIG-2011 & KM821934.1 & KM821935.1 & Irrua, Nigeria & Human & 2011 \\
\hline ISTH1058-NIG-2011 & KM821932.1 & KM821933.1 & Irrua, Nigeria & Human & 2011 \\
\hline ISTH1048-NIG-2011 & KM821930.1 & KM821931.1 & Irrua, Nigeria & Human & 2011 \\
\hline ISTH1038-NIG-2011 & KM821928.1 & KM821929.1 & Irrua, Nigeria & Human & 2011 \\
\hline ISTH1003-NIG-2011 & KM821926.1 & KM821927.1 & Irrua, Nigeria & Human & 2011 \\
\hline ISTH0595-NIG-2011 & KM821923.1 & KM821924.1 & Irrua, Nigeria & Human & 2011 \\
\hline ISTH0531-NIG-2011 & KM821921.1 & KM821922.1 & Irrua, Nigeria & Human & 2011 \\
\hline ISTH0230-NIG-2011 & KM821919.1 & KM821920.1 & Irrua, Nigeria & Human & 2011 \\
\hline ISTH0073-NIG-2011 & KM821917.1 & KM821918.1 & Irrua, Nigeria & Human & 2011 \\
\hline ISTH0047-NIG-2011 & KM821915.1 & KM821916.1 & Irrua, Nigeria & Human & 2011 \\
\hline ISTH0012-NIG-2011 & KM821913.1 & KM821914.1 & Irrua, Nigeria & Human & 2011 \\
\hline ISTH0009-NIG-2011 & KM821911.1 & KM821912.1 & Irrua, Nigeria & Human & 2011 \\
\hline Z0948-SLE-2011 & KM822131.1 & KM822132.1 & Sierra Leone & M. natalensis & 2011 \\
\hline Z0947-SLE-2011 & KM822129.1 & KM822130.1 & Sierra Leone & M. natalensis & 2011 \\
\hline LM778-SLE-2012 & KM822123.1 & KM822124.1 & Sierra Leone & M. natalensis & 2012 \\
\hline LM776-SLE-2012 & KM822121.1 & KM822122.1 & Sierra Leone & M. natalensis & 2012 \\
\hline LM765-SLE-2012 & KM822116.1 & KM822117.1 & Sierra Leone & M. natalensis & 2012 \\
\hline LM395-SLE-2009 & KM822114.1 & KM822115.1 & Sierra Leone & M. natalensis & 2009 \\
\hline LM222-SLE-2010 & KM822112.1 & KM822113.1 & Sierra Leone & M. natalensis & 2010 \\
\hline LM032-SLE-2010 & KM822110.1 & KM822111.1 & Sierra Leone & M. natalensis & 2010 \\
\hline G3278-SLE-2013 & KM821908.1 & KM821909.1 & Sierra Leone & Human & 2013 \\
\hline G3248-SLE-2013 & KM821905.1 & KM821906.1 & Sierra Leone & Human & 2013 \\
\hline G3234-SLE-2013 & KM821903.1 & KM821904.1 & Sierra Leone & Human & 2013 \\
\hline G3229-SLE-2013 & KM821901.1 & KM821902.1 & Sierra Leone & Human & 2013 \\
\hline G3206-SLE-2013 & KM821898.1 & KM821899.1 & Sierra Leone & Human & 2013 \\
\hline
\end{tabular}


TABLE 1 | Continued

\begin{tabular}{|c|c|c|c|c|c|}
\hline Isolate & Accession number (L segment) & Accession number (S segment) & Country of origin & Host & Year of isolation \\
\hline G3170-SLE-2013 & KM821896.1 & KM821897.1 & Sierra Leone & Human & 2013 \\
\hline G3151-SLE-2013 & KM821893.1 & KM821894.1 & Sierra Leone & Human & 2013 \\
\hline G3148-SLE-2013 & KM821891.1 & KM821892.1 & Sierra Leone & Human & 2013 \\
\hline G3106-SLE-2013 & KM821888.1 & KM821889.1 & Sierra Leone & Human & 2013 \\
\hline G3010-SLE-2013 & KM821881.1 & KM821882.1 & Sierra Leone & Human & 2013 \\
\hline G2944-SLE-2012 & KM821879.1 & KM821880.1 & Sierra Leone & Human & 2012 \\
\hline G2868-SLE-2012 & KM821873.1 & KM821874.1 & Sierra Leone & Human & 2012 \\
\hline G2723-SLE-2012 & KM821870.1 & KM821871.1 & Sierra Leone & Human & 2012 \\
\hline G2612-SLE-2012 & KM821866.1 & KM821867.1 & Sierra Leone & Human & 2012 \\
\hline G2587-SLE-2012 & KM821864.1 & KM821865.1 & Sierra Leone & Human & 2012 \\
\hline G2565-SLE-2012 & KM821862.1 & KM821863.1 & Sierra Leone & Human & 2012 \\
\hline G2557-SLE-2012 & KM821860.1 & KM821861.1 & Sierra Leone & Human & 2012 \\
\hline G2554-SLE-2012 & KM821858.1 & KM821859.1 & Sierra Leone & Human & 2012 \\
\hline G2431-SLE-2012 & KM821855.1 & KM821856.1 & Sierra Leone & Human & 2012 \\
\hline G2427-SLE-2012 & KM821853.1 & KM821854.1 & Sierra Leone & Human & 2012 \\
\hline G2405-SLE-2012 & KM821851.1 & KM821852.1 & Sierra Leone & Human & 2012 \\
\hline G2392-SLE-2012 & KM821849.1 & KM821850.1 & Sierra Leone & Human & 2012 \\
\hline G2363-SLE-2012 & KM821846.1 & KM821847.1 & Sierra Leone & Human & 2012 \\
\hline G2295-SLE-2012 & KM821840.1 & KM821841.1 & Sierra Leone & Human & 2012 \\
\hline G2280-SLE-2012 & KM821838.1 & KM821839.1 & Sierra Leone & Human & 2012 \\
\hline G2263-SLE-2012 & KM821836.1 & KM821837.1 & Sierra Leone & Human & 2012 \\
\hline G2259-SLE-2012 & KM821834.1 & KM821835.1 & Sierra Leone & Human & 2012 \\
\hline G2222-SLE-2011 & KM821831.1 & KM821832.1 & Sierra Leone & Human & 2011 \\
\hline G2197-SLE-2011 & KM821829.1 & KM821830.1 & Sierra Leone & Human & 2011 \\
\hline G2184-SLE-2011 & KM821827.1 & KM821828.1 & Sierra Leone & Human & 2011 \\
\hline G2165-SLE-2011 & KM821825.1 & KM821826.1 & Sierra Leone & Human & 2011 \\
\hline G2147-SLE-2011 & KM821823.1 & KM821824.1 & Sierra Leone & Human & 2011 \\
\hline G2141-SLE-2011 & KM821821.1 & KM821822.1 & Sierra Leone & Human & 2011 \\
\hline G1960-SLE-2011 & KM821819.1 & KM821820.1 & Sierra Leone & Human & 2011 \\
\hline G1792-SLE-2011 & KM821813.1 & KM821814.1 & Sierra Leone & Human & 2011 \\
\hline G1774-SLE-2011 & KM821811.1 & KM821812.1 & Sierra Leone & Human & 2011 \\
\hline G1727-SLE-2011 & KM821809.1 & KM821810.1 & Sierra Leone & Human & 2011 \\
\hline G1646-SLE-2011 & KM821805.1 & KM821806.1 & Sierra Leone & Human & 2011 \\
\hline G1529-SLE-2011 & KM821801.1 & KM821802.1 & Sierra Leone & Human & 2011 \\
\hline G1442-SLE-2011 & KM821799.1 & KM821780.1 & Sierra Leone & Human & 2011 \\
\hline G1200-LIB-2010 & KM821797.1 & KM821798.1 & Sierra Leone & Human & 2010 \\
\hline G1190-SLE-2010 & KM821795.1 & KM821796.1 & Sierra Leone & Human & 2010 \\
\hline G808-SLE-2010 & KM821791.1 & KM821792.1 & Sierra Leone & Human & 2010 \\
\hline G771-SLE-2010 & KM821788.1 & KM821789.1 & Sierra Leone & Human & 2010 \\
\hline G733-SLE-2010 & KM821786.1 & KM821787.1 & Sierra Leone & Human & 2010 \\
\hline G693-SLE-2009 & KM821784.1 & KM821785.1 & Sierra Leone & Human & 2009 \\
\hline G692-SLE-2009 & KM821782.1 & KM821783.1 & Sierra Leone & Human & 2009 \\
\hline G676-SLE-2009 & KM821780.1 & KM821781.1 & Sierra Leone & Human & 2009 \\
\hline G636-SLE-2009 & KM821778.1 & KM821779.1 & Sierra Leone & Human & 2009 \\
\hline G610-SLE-2009 & KM821776.1 & KM821777.1 & Sierra Leone & Human & 2009 \\
\hline G503-SLE-2009 & KM821774.1 & KM821775.1 & Sierra Leone & Human & 2009 \\
\hline G502-SLE-2009 & KM821772.1 & KM821773.1 & Sierra Leone & Human & 2009 \\
\hline Nig08-A19 & GU481073.1 & GU481074.1 & Jos, Nigeria & Human & 2008 \\
\hline Nig08-A18 & GU481071.1 & GU481072.1 & Jos, Nigeria & Human & 2008 \\
\hline Nig08-04 & GU481069.1 & GU481070.1 & Abakaliki, Nigeria & Human & 2008 \\
\hline Nig08-A47 & GU481079.1 & GU481080.1 & Irrua, Nigeria & Human & 2008 \\
\hline
\end{tabular}


TABLE 1 | Continued

\begin{tabular}{|c|c|c|c|c|c|}
\hline Isolate & Accession number (L segment) & Accession number (S segment) & Country of origin & Host & Year of isolation \\
\hline Nig08-A41 & GU481077.1 & GU481078.1 & Irrua, Nigeria & Human & 2008 \\
\hline Nig08-A37 & GU481075.1 & GU481076.1 & Irrua, Nigeria & Human & 2008 \\
\hline Bamba-R114 & KF478761.1 & KF478766.1 & Bamba, Mali & M. natalensis & 2012 \\
\hline Komina-R16 & KF478760.1 & KF478767.1 & Komina, Mali & M. natalensis & 2012 \\
\hline Soromba-R30 & KF478763.1 & KF478769.1 & Soromba, Mali & M. natalensis & 2012 \\
\hline Soromba-R & KF478762.1 & KF478765.1 & Soromba, Mali & M. natalensis & 2009 \\
\hline $\mathrm{NL}$ & AY179172.1 & AY179173.1 & Sierra Leone & Human (Lethal) & 2000 \\
\hline AV & AY179171.1 & AY179172.1 & Ghana/Ivory Coast & Human (Lethal) & 2000 \\
\hline Z148 & AY628204.1 & AY628205.1 & Zorzor, Liberia & Human (Non-lethal) & 1981 \\
\hline Macenta & AY628200.1 & AY628201.1 & Liberia & Human (Lethal) & 1984 \\
\hline BA366 & GU979513.1 & GU979514.1 & Guinea & M. natalensis & 2003 \\
\hline Josiah & HQ688674.1 & HQ688672.1 & Sierra Leone & Human (Lethal) & 1976 \\
\hline Pinneo-NIG-1969 & KM822127.1 & KM822128.1 & Lassa, Nigeria & Human (Non-lethal) & 1969 \\
\hline
\end{tabular}

\section{The Fifth LASV Lineage Emerged during the Colonial Period}

In order to determine when the lineage emerged, we performed a BEAST analysis using the trees obtained from MrBayes. By providing the year of isolation for each isolate, we were able to approximate the emergence of lineages IV and V from their nearest common ancestor. Analysis of all three complete genes estimates the emergence of lineage $\mathrm{V}$ to have occurred roughly 250 years ago (Figure 2), which coincides with movement throughout the region during the colonial period of West Africa. While both $\mathrm{S}$ segment genes estimate the most recent common ancestor between lineages IV and V to have existed between 200 and 300 years ago, the estimated range is much larger in the LP analysis (141-416 years ago). The most recent common ancestor of the lineage $\mathrm{V}$ group was approximately 114 years ago, with a range of 225-30.

Movement of the virus from Nigeria to the Mano river region is predicted to have occurred between roughly between $300-$ 500 years ago with respect to the $S$ segment genes (Figure 2). However, the range for the LP gene is much larger (190-693 years ago). Western movement of LASV from Nigeria likely occurred during the pre-colonial period of West Africa between the years 1500 and $1700 \mathrm{AD}$, although the virus appears to have been circulating in Nigeria prior to 1300 AD. Additionally, the most recent common ancestor of LASV and Mopeia virus (MOPV) is estimated to have existed between 0 and $700 \mathrm{AD}$ based on S segment gene analysis (Figure 2). The origin of LASV in the Nigerian region is most likely, but the sampling of LASV is still heavily biased in favor of certain regions and therefore increased sampling is required to fully determine the origins and movements of this virus.

\section{Discussion}

This study represents the first phylogenetic analysis of LASV that includes every available isolate from the traditional four lineages, as well as every available isolate from Mali and the Ivory Coast. While the lineage hierarchy for both the GPC and NP supports the results from the original analysis (Bowen et al., 2000), lineage I is not the most basal lineage in the LP analysis. However, this is not strongly supported by the posterior probability suggesting that until more strains are isolated it will be difficult to resolve with the LP gene. It is possible for two closely related arenaviruses to reassort (Lukashevich, 1992). It is possible that a reassortment event occurred between ancestral lineage I and lineage II strains, but as previous studies have not detected any reassortment events among LASV strains (Vieth et al., 2004; Emonet et al., 2006) this seems unlikely. However, the lineage I isolate was not available at the time. Our results indicate that lineage I remains the most basal lineage based on full-length GPC analysis. However, these findings do not support the previous findings by Ehichioya et al., which places lineage II as the most basal lineage for GPC. Evidence of recombination between arenavirus species has been described within the New World arenaviruses (Fulhorst et al., 1999; Weaver et al., 2000), which could explain different groupings between two genes in the same segment. However, no evidence of recombination was detected in their analysis (Ehichioya et al., 2011). It is possible that the different alignment method utilized prior to our analysis contributed to the different outcome.

The discrepancy between the GPC gene and the NP and LP genes in the topology of lineage IV is likely due to the additional number of strains belonging to lineage IV in the GPC gene tree. As full genome sequences of these strains become available we would expect these observed differences to be resolved.

Analysis of all three full-length genes supports the emergence of a fifth LASV lineage, which appears to have diverged from a common ancestor with lineage IV around 250 years ago. Conflict situations and the resulting human movement have been described to perturb the virus relationship with its peridomestic natural host, M. natalensis. Movement of $M$. natalensis over large distances, such as transportation by ship or even through movement of refugees during conflicts, can lead to foci of transmission among the local $M$. natalensis population (Lalis et al., 2012). Emergence of the fifth lineage may have therefore occurred due to human movement during the colonial period. 


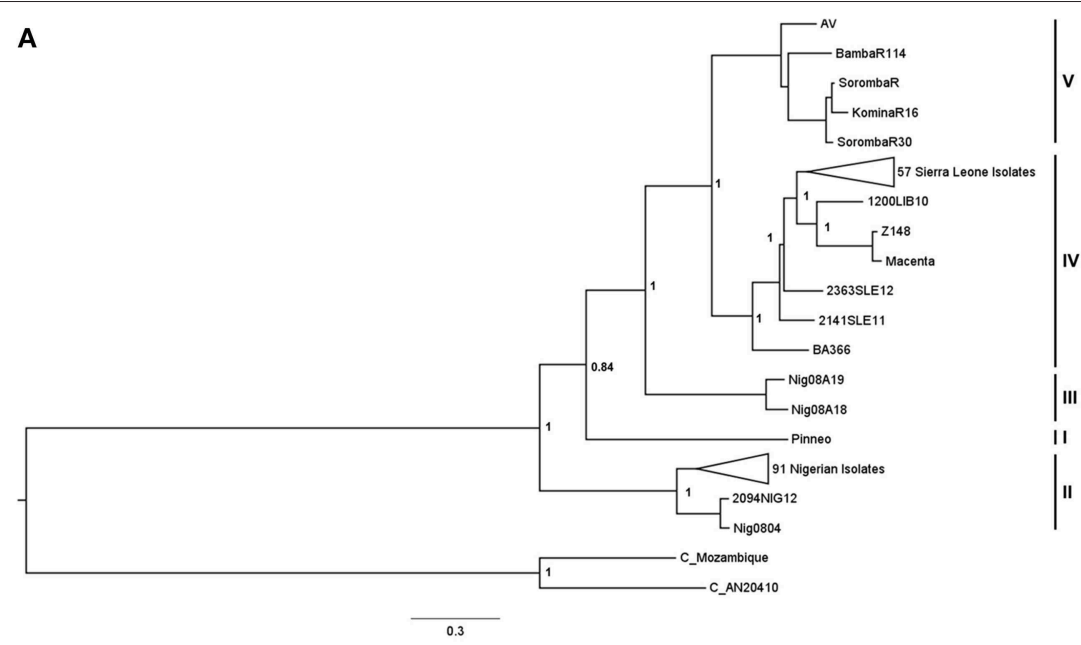

B

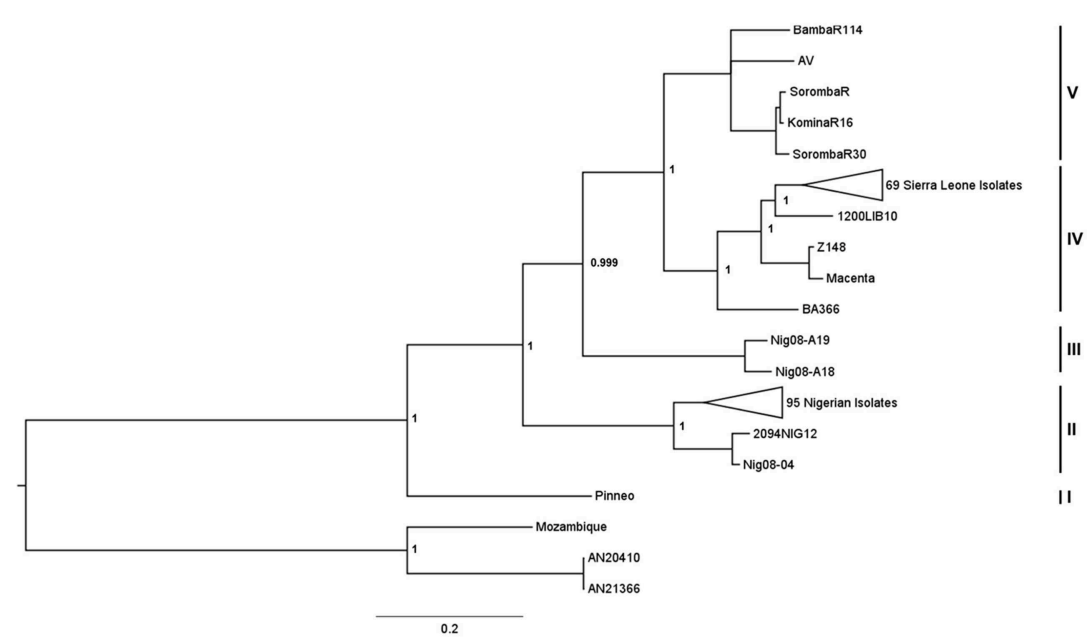

C

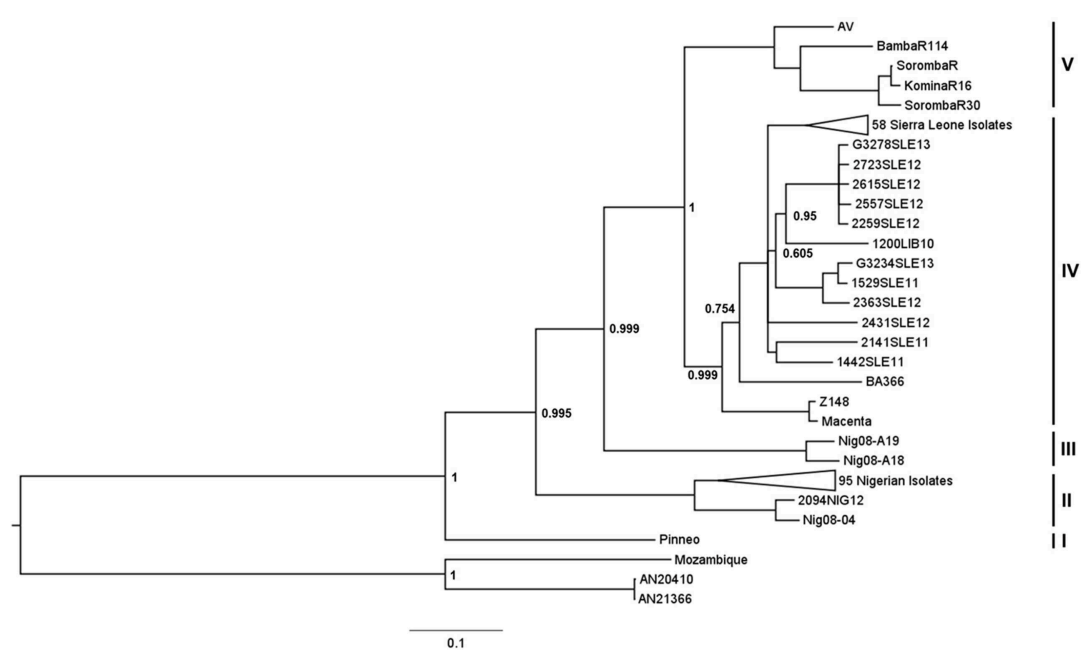

FIGURE 1 | Bayesian analysis of complete LP, NP, and GPC nucleotide sequences. Complete open reading frames were aligned using MUSCLE, and analyzed using the Bayesian MCMC approach. The resulting trees for LP (A), NP (B), and GPC (C) were visualized using FigTree v1.4.2 and rooted using two representative Mopeia virus isolates. To better visualize distinct lineages, several Sierra Leonian, and Nigerian isolates were collapsed. These sections of the trees are provided in Figures S1-S6. Posterior probabilities are represented as node labels for the main clades, with 1 being $100 \%$ probability. The isolates are grouped by their respective lineages, as represented by the bars to the right of the trees. The scale represents nucleotide changes per site per year. 


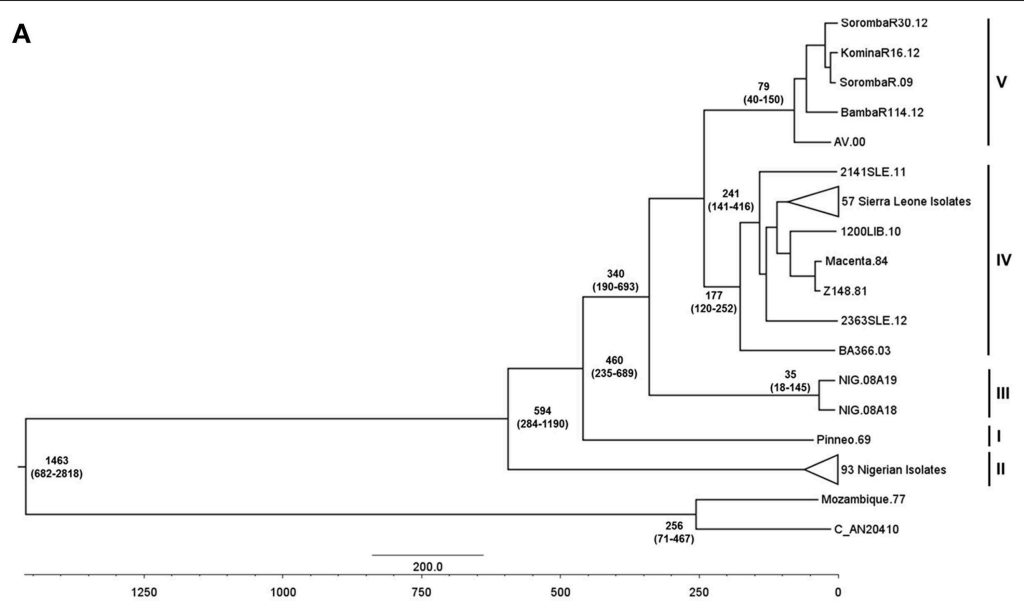

B

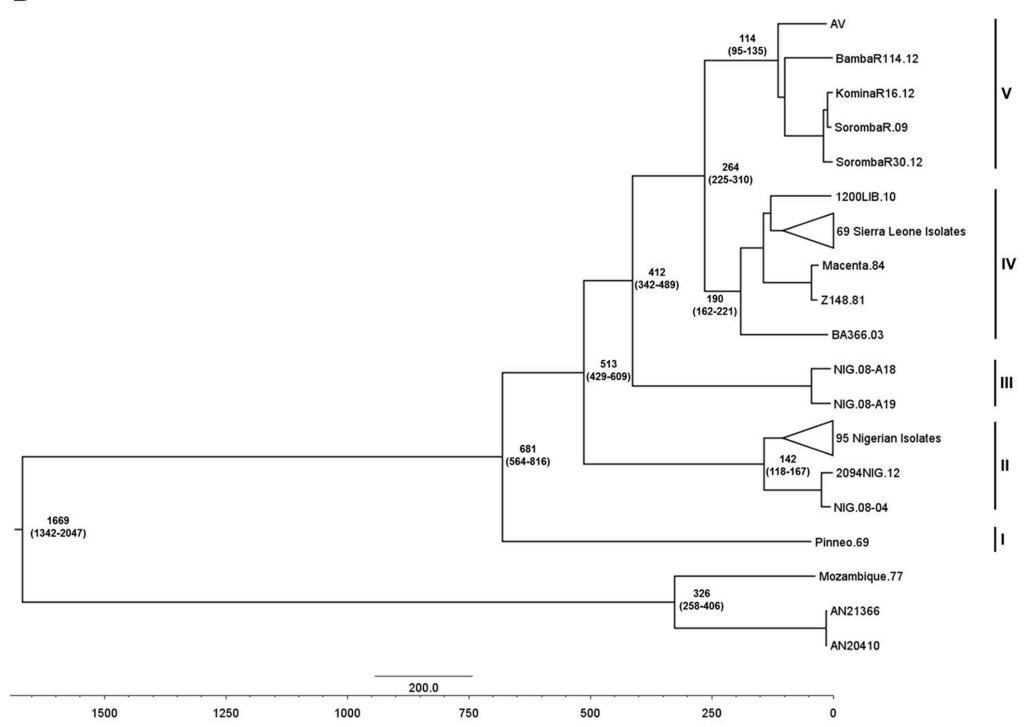

C

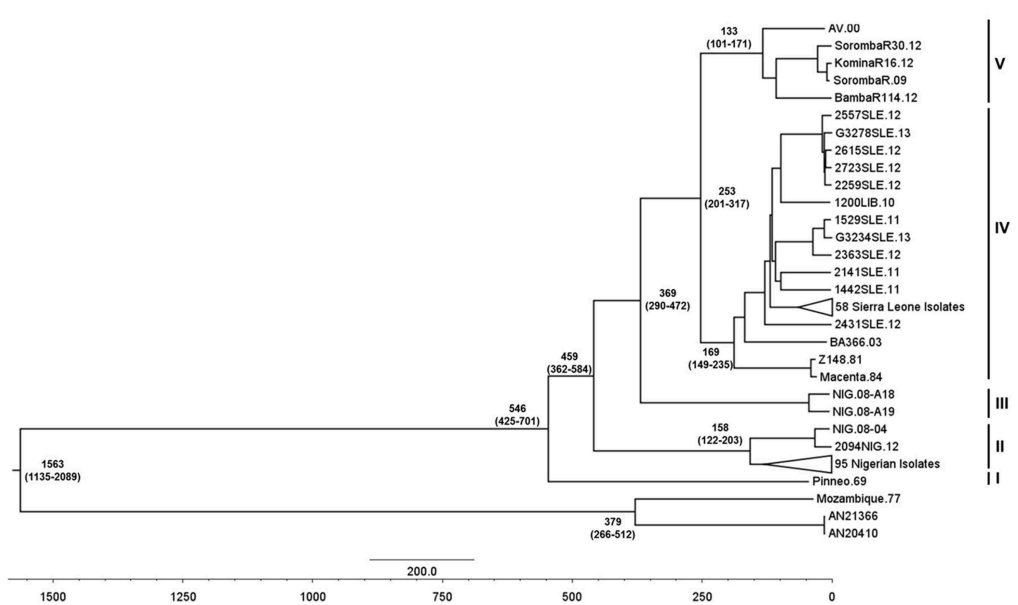

FIGURE 2 | BEAST analysis of complete LP, NP, and GPC nucleotide sequences. Complete open reading frames were aligned using MUSCLE, and analyzed using the Bayesian MCMC approach. The resulting trees for LP (A), NP (B), and GPC (C) were visualized using FigTree v1.4.2 and rooted using two representative Mopeia virus isolates. To better visualize distinct lineages, several Sierra Leonian and Nigerian isolates were collapsed, and these sections of the trees are provided in Figures S7-S12. The node ages, in years, are included on the major nodes, with the 95\% confidence ranges displayed in parentheses below the median node ages. The isolates are grouped by their lineages, as represented by the bars to the right of the trees. The reverse axis represents the age, in years, from the most recent isolate. 


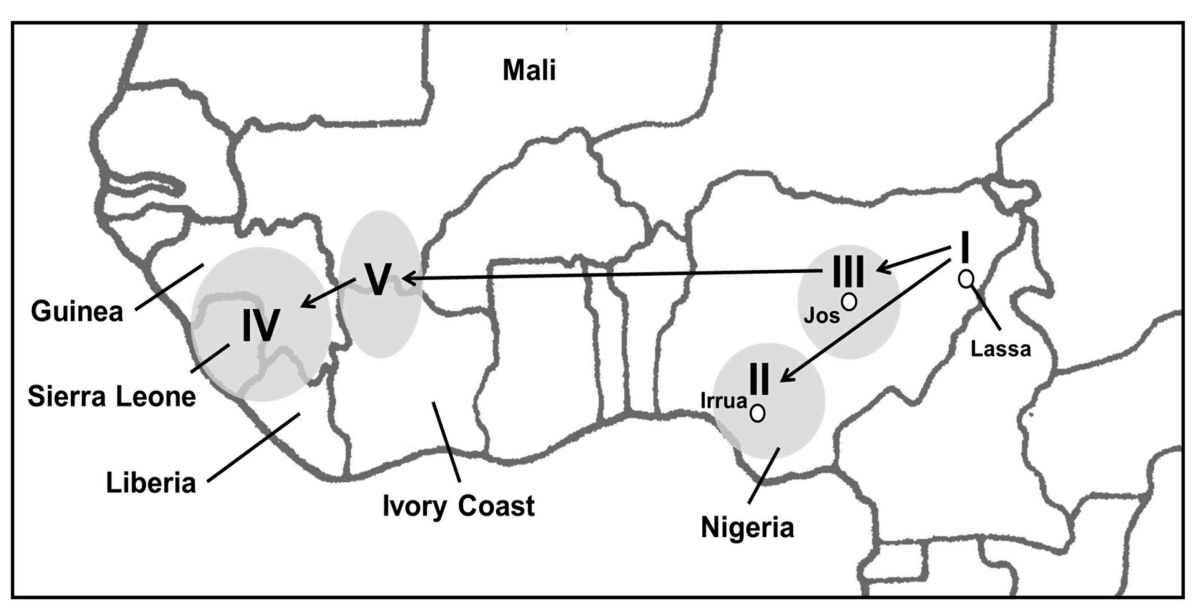

FIGURE 3 | Map of LASV movement across West Africa. Based on the phylogenetic data, LASV has gradually spread west, beginning in Eastern Nigeria. Ehichioya et al. has previously illustrated the movement of LASV within Nigeria (Ehichioya et al., 2011). The isolates of lineage $V$ and the BA366 Liberian isolate share a more direct common ancestor with lineage III than the Sierra Leone Isolates share with lineage III isolates. This suggests that the virus was likely present in Mali, the Ivory Coast, and Liberia prior to establishing itself in Sierra Leone. The areas from which the isolates were collected are shaded in gray.

When comparing the AV strain to the Sierra Leone strains, the AV strain is more closely related to the Liberian BA366 strain and the Nigerian lineage III strains. Based on this relationship between the Nigerian isolates and the isolates of lineages IV and V, it appears likely that the virus spread gradually west, establishing focal points of transmission in the Ivory Coast and Mali prior to its arrival in Liberia, Guinea, and Sierra Leone. Although the prediction varies between the three genes, this migration likely occurred during the precolonial and colonial periods, possibly arriving in Mali and the Ivory Coast between 300 and 450 years ago and Guinea or Liberia around 250 years ago. This is supported by the substitution rate estimates previously calculated, suggesting that the spread of LASV across West Africa occurred between 300 and 800 years ago (Ehichioya et al., 2011). Andersen et al. recently performed a similar phylogenetic analysis using a large number of complete L segment sequences. Their conclusions were almost identical to our own, indicating a gradual movement of LASV across West Africa (Andersen et al., 2015). In both analyses, the virus is predicted to have arrived in Mali and the Ivory Coast a full century prior to its arrival in Sierra Leone (Figure 3).

In conclusion, this study reports that a fifth LASV lineage exists within Mali and the Ivory Coast, sharing a sister relationship with the isolates of lineage IV. Despite the apparent

\section{References}

Andersen, K. G., Shapiro, B. J., Matranga, C. B., Sealfon, R., Lin, A. E., Moses, L. M., et al. (2015). Clinical sequencing uncovers origins and evolution of Lassa Virus. Cell 162, 738-750. doi: 10.1016/j.cell.2015. 07.020

Atkin, S., Anaraki, S., Gothard, P., Walsh, A., Brown, D., Gopal, R., et al. (2009). The first case of Lassa fever imported from Mali to the United Kingdom, February 2009. Euro Surveill. 14:19145. Available online at: http:// www.eurosurveillance.org/ViewArticle.aspx?ArticleId=19145 presence of the virus within Mali over the last 200 years, it is peculiar that LF cases have only begun to surface within the last decade. The recent emergence of reported cases may be due to the lack of surveillance in the region, particularly in villages with limited access to healthcare. Nevertheless, the presence of a genetically distinct LASV lineage within this region will likely serve to increase the genetic variability in an already diverse virus species. These findings highlight the importance of considering genetic diversity among LASV isolates when developing and testing treatments and vaccine candidates.

\section{Acknowledgments}

This research was supported by the NIH grant: UC7 5UAI094660 for operational support of the Galveston National Laboratory, as well as funding from the UTMB Sealy Center for Vaccine Development.

\section{Supplementary Material}

The Supplementary Material for this article can be found online at: http://journal.frontiersin.org/article/10.3389/fmicb. 2015.01037

Bowen, M. D., Rollin, P. E., Ksiazek, T. G., Hustad, H. L., Bausch, D. G., Demby, A. H., et al. (2000). Genetic diversity among Lassa virus strains. J. Virol. 74, 6992. doi: 10.1128/JVI.74.15.6992-7004.2000

Demby, A. H., Inapogui, A., Kargbo, K., Koninga, J., Kourouma, K., Kanu, J., et al. (2001). Lassa fever in Guinea: II. Distribution and prevalence of Lassa virus infection in small mammals. Vector Borne Zoonotic Dis. 1, 283-297. doi: $10.1089 / 15303660160025912$

Drummond, A. J., Ho, S. Y., Phillips, M. J., and Rambaut, A. (2006). Relaxed phylogenetics and dating with confidence. PLoS Biol. 4:e88. doi: 10.1371/journal.pbio.0040088 
Drummond, A. J., and Rambaut, A. (2007). BEAST: Bayesian evolutionary analysis by sampling trees. BMC Evol. Biol. 7:214. doi: 10.1186/1471-2148-7-214

Drummond, A. J., Rambaut, A., Shapiro, B., and Pybus, O. G. (2005). Bayesian coalescent inference of past population dynamics from molecular sequences. Mol. Biol. Evol. 22, 1185-1192. doi: 10.1093/molbev/ msil03

Drummond, A. J., Suchard, M. A., Xie D., and Rambaut, A. (2012). Bayesian phylogenetics with BEAUti and the BEAST 1.7. Mol. Biol. Evol. 29, 1969-1973. doi: $10.1093 / \mathrm{molbev} / \mathrm{mss} 075$

Edgar, R. C. (2004). MUSCLE: multiple sequence alignment with high accuracy and high throughput. Nucleic Acids Res. 32, 1792-1797. doi: 10.1093/nar/gkh340

Ehichioya, D. U., Hass, M., Becker-Ziaja, B., Ehimuan, J., Asogun, D. A., FichetCalvet, E., et al. (2011). Current molecular epidemiology of Lassa virus in nigeria. J. Clin. Microbiol. 49, 1157-1161. doi: 10.1128/JCM.01891-10

Emonet, S., Lemasson, J. J., Gonzalez, J. P., de Lamballerie, X., and Charrel, R. N. (2006). Phylogeny and evolution of old world arenaviruses. Virology 350, 251-257. doi: 10.1016/j.virol.2006.01.026

Fulhorst, C. F., Bowen, M. D., Salas, R. A., Duno, G., Utrera, A., Ksiazek, T. G., et al. (1999). Natural rodent host associations of Guanarito and Pirital viruses (family Arenaviridae) in central Venezuela. Am. J. Trop. Med. Hyg. 61, 325-330.

Gouy, M., Guindon, S., and Gascuel, O. (2010). SeaView version 4: a multiplatform graphical user interface for sequence alignment and phylogenetic tree building. Mol. Biol. Evol. 27, 221-224. doi: 10.1093/molbev/msp259

Günther, S., Emmerich, P., Laue, T., Kühle, O., Asper, M., Jung, A., et al. (2000). Imported lassa fever in Germany: molecular characterization of a new Lassa virus strain. Emerging Infect. Dis. 6, 466-476. doi: 10.3201/eid0605.000504

Huelsenbeck, J. P., and Ronquist, F. (2001). MRBAYES: Bayesian inference of phylogeny. Bioinformatics 17, 754-755. doi: 10.1093/bioinformatics/1 7.8.754

Lalis, A., Leblois, R., Lecompte, E., Denys, C., Ter Meulen, J., and Wirth, T. (2012). The impact of human conflict on the genetics of Mastomys natalensis and Lassa virus in West Africa. PLoS ONE 7:e37068. doi: 10.1371/journal.pone.0037068

Lecompte, E., Fichet-Calvet, E., Daffis, S., Koulémou, K., Sylla, O., Kourouma, F., et al. (2006). Mastomys natalensis and Lassa fever, West Africa. Emerg. Infect. Dis. 12, 1971-1974. doi: 10.3201/eid1212.060812
Lukashevich, I. S. (1992). Generation of reassortants between African Arenaviruses. Virology 188, 600-605. doi: 10.1016/0042-6822(92)90514-P

Ogbu, O., Ajuluchukwu, E., and Uneke, C. J. (2007). Lassa fever in West African sub-region: an overview. J. Vector Borne Dis. 44, 1-11.

Ronquist, F., and Huelsenbeck, J. P. (2003). MRBAYES 3: Bayesian phylogenetic inference under mixed models. Bioinformatics 19, 1572-1574. doi: 10.1093/bioinformatics/btg180

Safronetz, D., Lopez, J. E., Sogoba, N., Traore, S. F., Raffel, S. J., Fischer, E. R., et al. (2010). Detection of Lassa Virus, Mali. Emerg. Infect. Dis. 16, 1123-1126. doi: 10.3201/eid1607.100146

Safronetz, D., Sogoba, N., Lopez, J. E., Maiga, O., Dahlstrom, E., Zivcec, M., et al. (2013). Geographic distribution and genetic characterization of Lassa virus in sub-Saharan Mali. PLoS Negl. Trop. Dis. 7:e2582. doi: 10.1371/journal.pntd.0002582

Sogoba, N., Feldmann, H., and Safronetz, D. (2012). Lassa fever in West Africa: evidence for an expanded region of endemicity. Zoonoses Public Health. 2, 43-47. doi: 10.1111/j.1863-2378.2012.01469.x

Vieth, S., Torda, A. E., Asper, M., Schmitz, H., and Günther, S. (2004). Sequence analysis of L RNA of Lassa virus. Virology 318, 153-168. doi: 10.1016/j.virol.2003.09.009

Weaver, S. C., Salas, R. A., de Manzione, N., Fulhorst, C. F., Duno, G., Utrera, A., et al. (2000). Guanarito virus (Arenaviridae) isolates from endemic and outlying localities in Venezuela: Sequence comparisons among and within strains recovered from Venezuelan hemorrhagic fever patients and rodents. Virology 266, 189-195. doi: 10.1006/viro.1999.0067

Conflict of Interest Statement: The authors declare that the research was conducted in the absence of any commercial or financial relationships that could be construed as a potential conflict of interest.

Copyright (c) 2015 Manning, Forrester and Paessler. This is an open-access article distributed under the terms of the Creative Commons Attribution License (CC BY). The use, distribution or reproduction in other forums is permitted, provided the original author(s) or licensor are credited and that the original publication in this journal is cited, in accordance with accepted academic practice. No use, distribution or reproduction is permitted which does not comply with these terms. 